\title{
DOES ATHEISM ENTAIL A CONTRADICTION?
}

\author{
JOSHUA RASMUSSEN \\ https:/ / orcid.org/0000-0003-3578-0644 \\ Azusa Pacific University \\ Department of Philosophy \\ Fontana, California \\ U.S.A. \\ jrasmussen@apu.com
}

\author{
Article info \\ CDD: 200.1 \\ Received: 17.06.2021; Accepted: 15.08.2021 \\ https://doi.org/10.1590/0100-6045.2021.V44N4.JR
}

\section{Keywords \\ Necessary existence \\ Ontological argument \\ God's necessity \\ Perfect being theology \\ Natural theology}

\begin{abstract}
I consider whether a contradiction may be deducible from the proposition that God does not exist. First, I expose a candidate counterexample to a key premise in Swinburne's argument against the deducibility of a contradiction from God's non-existence. Second, I present two new strategies one might use to deduce a contradiction. Both strategies make use of Tarski's Tschema together with developments in other theistic arguments. One argument is a conceptualist argument from necessary truth for a necessary mind, and the other is a two-stage contingency argument for the same conclusion. The purpose of this article is not to decisively defend these arguments, but to expose new territory relevant to investigating the nature of God's necessity (if God exists).
\end{abstract}




\section{Introduction}

It is generally thought that atheism is at least logically possible. In the history of natural theology, the primary type of argument that purports to deduce a contradiction from denying the existence of God is the ontological argument. While there has been a resurgence of interest in developing new ontological arguments, most philosophers of religion (including theists) do not rank ontological arguments as the most dialectically productive, at least not in their traditional forms. ${ }^{1}$ Moreover, when theist philosophers seek to support theism with an argument (e.g., Swinburne 1979, Collins 2009, Rasmussen 2019, etc.), their arguments do not take a purely a priori form. In general, natural theology has proceeded under the premise that atheism is at least logically consistent.

However, I have not seen much attention given to the question of whether a contradiction could be deduced from atheism. The only direct argument against such a deduction in recent literature (as far as I have seen) depends on the premise that, in general, a contradiction cannot be deduced from denying the existence of anything, whatever it is (see Swinburne 2012). Yet, I believe there is good reason to reject this premise, as I will seek to show shortly.

Moreover, there are ways one might attempt to derive a contradiction from atheism without appealing to premises of

\footnotetext{
1 There have been notable recent developments on ontological arguments, and it would be premature to suggest that none of these can work, or that they have no dialectical value. My observation here is just that these arguments are not typically regarded (even by their proponents) as the most dialectically effective of theistic arguments. (For a review of recent developments in ontological arguments, see Goldschmidt 2020.)
} 
an ontological argument. In this article, I will present two examples to illustrate a general strategy. Both examples proceed from the root premise that 'there is no god' entails (via the T-schema) 'it is true that there is no god'. From here, I suggest how one may derive two key propositions: that something is true and that something exists. One may then plug these propositions into certain classical arguments for a minimal theism, as I will explain. These arguments highlight a way of making use of other classical arguments (arguments that a theist philosopher may already have some sympathy with) to show that God's existence is logically necessary.

Before I proceed to the arguments, I'd like to highlight a few reasons why the question of the logical necessity of theism is relevant to projects in philosophy of religion. First, the question of the logical necessity of theism is relevant to perfect being theology. According to perfect being theology, God is a perfect being. One might think that a perfect being would intuitively enjoy necessary existence in the strongest sense of "necessary." However, Swinburne has argued that the strongest sense of "necessary" is logical necessity, and that no being can exist in that strong of sense. If he is right, then either the concept of a perfect being is incoherent or a perfect being cannot enjoy such a strong grip on existence. Second, on some theistic models, God anchors (grounds or contains) all necessary truths, including logical necessities (cf. Anderon and Welty 2011). On these models, God's existence would be as secure as the existence of the logically necessary truths. These models turn, then, on the logical possibility of atheism. Third and finally, it is interesting to discover a general category of a priori theistic arguments (outside ontological arguments).

Here is the roadmap for this article. First, I'll provide some general remarks on what it means for atheism to be logically possible. Then I'll assess certain general motivations for thinking that atheism does not entail a contradiction. 
Next, I'll get on the table two strategies to deduce a contradiction. My goal is not to decisively defend these arguments, but to chart new territory relevant to the question of whether atheism entails a contradiction. In the conclusion, I'll share where I currently stand on the question.

\section{How to Deduce a Contradiction}

Let us get clearer on what would it mean for atheism to be self-contradictory. By "atheism," I mean to express the thesis that there is no god of any kind. While there may be many ways to qualify as a god, for our purposes, I shall stipulate this sufficient condition: a necessarily existent mind qualifies as a "god."

By " $x$ is self-contradictory," I mean that $x$ entails a contradiction. When I say that $\mathrm{x}$ entails a contradiction, I mean that one can tease out the contradiction a priori (i.e., by reason) - at least in principle. To illustrate, consider the proposition that $7+5=15$. This proposition does not explicitly contain a contradiction, for it does not have the form $A$ and not $A$. However, from other a priori principles (e.g., axioms and definitions), we can deduce a contradiction. For example, by reason, we can see these truths: (i) $7+5=$ 12 , and (ii) $12 \neq 15$, and (iii) if $7+5 \neq 15$, then it is not true that $7+5=15$. From here we can deduce that $7+5=15$ is only true if it is not true that $7+5=15$. And we have a contradiction.

On this account, we can distinguish between a narrow deduction and a broad deduction, or what Rumfitt (2010) calls "absolute logical consequence." A narrow deduction is limited to certain canonical truths or inference rules (such as double negation, universal instantiation, modus ponens, etc.). Narrow deductions have historically been used to establish so-called "analytic" truths. Narrow deduction is too 
limited to deduce every a priori truth (e.g., that no person could be a number, that justice is a virtue, that nothing can be a proper part of itself, and so on). Broad deductions allow for a deduction via any a priori truth of reason, whether canonical or not. Broad deductions are not limited to principles that humans have happened to canonize. Thus, when I say that $<7+5=15>$ entails a contradiction, I mean that a contradiction is deducible from some a priori truths of reason (whether narrow or broad).

I intend to use the term "truth of reason" in a broad way to include any general truth that one can see a priori. While there are debates about the existence and nature of a priori knowledge, for our purposes, I shall assume there are truths that one can see a priori. ${ }^{2}$ If there are truths of reason, they include such truths as $7+5=12$, for any $\mathrm{A}, \mathrm{A}=\mathrm{A}$, people cannot become numbers, circles cannot have angles, and so on. I say each of these are possible objects of reason (i.e., truths that one can see by reason).

Note that truths of reason need not be seen with 100\% clarity or be uncontroversial. It is controversial that $7+5=$ 12; certain fictionalists argue that this proposition is false. But controversy does not by itself disqualify a proposition from being a possible object of reason (e.g., when all obstacles are removed). A principle can count as a truth of reason even if no one (yet) perceives it, or if there is controversy over its truth.

To avoid being overly hasty in our judgment that something is consistent with reason, we must be careful to distinguish between not seeing an entailment and seeing no entailment. Perhaps no one has seen an entailment from atheism to a contradiction, but it does not follow that there is no entailment.

${ }^{2}$ For a defense of a priori reasoning as foundational to science and empirical inferences, see Huemer 2017.

Manuscrito - Rev. Int. Fil. Campinas, v. 44, n. 4, pp. 31-48, Oct.-Dec. 2021. 
A final note of clarification: I shall talk about deductions between propositions, where a proposition is what is expressed by a sentence token. This way of talking is not essential to my arguments. If one prefers, one may translate my arguments in terms of deductions between sentences (or sentence tokens). For example, if I say the proposition that there is no god entails the proposition that it is true that there is no god, one may instead say 'there is no god' entails 'it is true that there is no god'. ${ }^{3}$

Given these clarifications, we can be more precise about the question at hand. The question is whether atheism is selfcontradictory. In other words, does the proposition $<$ there is no god $>$ entail via reason alone the proposition $<$ there is a god> (e.g., a necessary mind)? We will investigate this question next.

\section{The Argument from Truth}

Let us begin with a reason one might think a contradiction is not deducible from atheism. Recall the general premise we considered earlier. The premise is this: a contradiction cannot be deduced from denying the existence of anything (whatever it is). If this premise is true, then there is no hope of deducing a contradiction from denying the existence of God. Is this premise true?

I said I have a reason to doubt the general premise. Here is my reason:

${ }^{3}$ Here is a fuller translation of entailment in terms of sentence tokens: if $\mathrm{s}_{1}$ entails $\mathrm{s}_{2}$, then necessarily, if $\mathrm{s}_{1}$ and $\mathrm{s}_{2}$ exist, and if $\mathrm{s}_{1}$ is true, then $\mathrm{s}_{2}$ is also true. 
1. Suppose there is no truth.

2. Then it is true that there is no truth.

3. Therefore, if there is no truth, then there is a truth (that there is no truth).

4. Therefore, $<$ there is no truth $>$ entails $<$ there is a truth $>$ - a contradiction.

This argument deduces a contradiction from denying the existence of truths. So if this argument is sound, then we have a counterexample to the general premise that a contradiction cannot be deduced from denying the existence of something.

Let's unpack the argument a bit. The inference from (1) to (2) is licensed by Tarski's T-schema: $\mathrm{S}$ is true iff and only if $\mathrm{S}$. We may convert this schema into a proposition that quantifies over propositions (else: sentences): for any propositions, $p$ and $<p$ is true $>, p$ is true if and only if $<p$ is true $>$ is true. My claim is that it is possible to see a priori this entailment link between $\mathrm{p}$ and $\langle p$ is true $>$. From here, we can deduce $<p$ is true $>$ exists from the general premise that whatever is true exists. ${ }^{4}$ It then follows that there is a truthnamely $p$. Therefore, the starting supposition that there is no truth entails a contradiction.

Note that seeing something by reason does not preclude seeing it by other means as well. I think we can see by reason the inference from $<p$ is true $>$ to $<p$ exists $>$. Meanwhile, we can also see that $<p$ exists $>$ is true directly by seeing $p$ itself (e.g., in our minds or on paper). The fact that we can see that $p$ exists directly does not preclude seeing by reason that $<p$ is true $>$ entails $<p$ exists $>$. The same point applies to the

\footnotetext{
${ }^{4}$ One might see this premise as an instance of serious actualism - the general thesis that whatever has a property or stands in some relation to something in a possible world also exists at that world. In other words, properties and relations are existence-entailing.
} 
inference from $p$ to $<p$ is true $>$. Perhaps we can see this inference only if $p$ and $<p$ is true $>$ exist, which we can then verify directly. That is consistent with our also being able to see the inference itself a priori.

So, it seems to me that we have a counterexample to the general premise that a negative existential cannot entail a contradiction. For the proposition, <there is no truth $>$, is a negative existential. And it entails a contradiction.

While I do not claim that this argument is indubitable, I believe it advances the dialectic. I presented a version of this argument to Richard Swinburne (in a keynote exchange at the American Philosophical Association). His response was to grant the argument. He then moved away from the general premise (about all negative existential statements) to a more specific premise (about certain negative existential statements). In particular, instead supposing that a contradiction cannot be deduced from denying the existence of just anything (including truths), Swinburne put forward the more specific premise that denying the existence of concrete substances (i.e., things with causal powers) does not entail a contradiction.

Let us consider, then, this more specific premise: <there are no concrete substances $>$ entails a contradiction. Call this premise, "the substance premise." Is the substance premise true?

While I expect any argument for or against the substance premise will be controversial, here is a reason someone with conceptualist (or nominalist ${ }^{5}$ ) sympathies might be skeptical of the substance premise:

1. Suppose there is no concrete substance.

5 A nominalist could give a parallel argument based on the reduction of truth-bearers to concrete sentence tokens.

Manuscrito - Rev. Int. Fil. Campinas, v. 44, n. 4, pp. 31-48, Oct.-Dec. 2021. 
2. Then it is true that there is no concrete substance.

3. Therefore, there is a truth.

4. Necessarily, if there is a truth, then there is a truth-bearer.

5. Necessarily, if there is a truth-bearer, then there is a mind.

6. Necessarily, a mind is (or belongs to) a concrete substance.

7. Therefore, there is a concrete substance.

8. Therefore, $<$ there is no concrete substance $>$ entails $<$ there is a concrete substance $>$ - a contradiction.

The first part of the argument follows the same reasoning as in the previous argument from $<$ there is no truth $>$ to $<$ there is a truth>. Next, we have the conceptualist piece: this argument attempts to move from the existence of truth to the existence of a mind. This piece will appeal to a conceptualist. A conceptualist might think that truth-bearers are contents of thoughts, which in turn are grounded in particular thoughts in a mind. A mind qualifies as a concrete substance (on the standard definition of "concrete substance" as being something with causal powers), since it has the causal power to produce thoughts.

Of course, those who are not conceptualists about truthbearers will not accept this argument. Still, it is significant that the debate over conceptualism proceeds in the a priori landscape. When theorists seek to provide an account of truth-bearers, they typically appeal to general a priori principles and conceptual analysis. For this reason, the substance premise is in the terrain of a priori inquiry.

Moreover, even if one does not accept the above argument, it does not follow that one must accept the substance premise. I want to emphasize again that not seeing 
a contradiction is not the same as seeing the impossibility of deducing a contradiction. If one does not see that $<$ there is no substance $>$ entails a contradiction, it does not follow that $<$ there is no substance $>$ is logically possible. Entailments can run behind mountains out of one's sight. To be sure, I am not saying that no one could have any reason to think the substance premise is true. My point here is that finding such a reason takes more than just noticing that one is not personally seeing a contradiction.

So far, we have been getting pieces of a larger argument on the table. This larger argument is a conceptualist argument for the thesis that atheism entails a contradiction. We are now ready to put the pieces together to form the following argument:

1. Suppose there is no god.

2. Then it is true that there is no god.

3. Therefore, if there is no god, then there is a truth (that there is no god).

4. Necessarily, if there is a truth, then there is a necessary truth (e.g., that truth entails existence).

5. Necessarily, if there is a necessary truth, then there is a necessary mind.

6. Therefore, there is a god (e.g., a necessary mind).

7. Therefore, $<$ there is no god $>$ entails <there is a god $>$ - a contradiction.

While the steps in this argument will certainly also be controversial, a conceptualist may have independent reasons to support each premise by her lights. Previously, we saw that a conceptualist is in position to think that truth-bearers depend on a mind. The argument just given links necessary truth to a necessary mind. This piece is a typical part of conceptualist argument for theism; cf. Smith 1994. 
Let us have a closer look at the link from necessary truth to a necessary mind. Here is how a conceptualist might support the link. First, there is an argument from necessary truth to the necessary existence of truth-bears. Consider this version of that argument (based on the argument in Rasmussen 2013):

5.1. If $p$ is necessarily true, then necessarily, $p$ is necessarily true.

5.2. Necessarily, whatever is necessarily true exists.

5.3. Therefore, if $p$ is necessarily true, then necessarily, $p$ exists.

Premise 5.1. is an objectual interpretation of S4 logic. The idea is that necessity is itself necessary. For example, if $2+2$ $=4$ is necessary, then it is not merely contingent that $2+2$ $=4$ is necessary; its necessity is also necessary. Premise 5.2 records again the premise that truth entails existence-i.e., something cannot be true unless it exists.

Next, we complete the argument using the conceptualist premise that truth-bearers depend on a mind-e.g.:

5.4. If a truth-bearer exists, then a mind exists.

5.5. Therefore, if some truth-bearer necessarily exists, some mind necessarily exists.

5.6. Therefore, some mind necessarily exists.

This argument shows how a conceptualist may already be in position to think that atheism entails a contradiction.

As before, a non-conceptualist will not accept the final step in this argument. But it is still significant to see this path, especially since conceptualism does not itself presuppose theism. Non-theists occupy the spectrum of views about abstracta, including conceptualism, Platonism, and nominalism. Moreover, the usual motivations for conceptualism do not depend on premises about the existence of God. Rather, they depend on general considerations about the nature of abstracta and their relations to mental items. Whatever one's theory of 
abstracta, I think it is significant to see this reason-based path via conceptualist lights (even if not everyone will take it).

\section{The Argument from Existence}

Here is a second strategy for deducing a contradiction from <there is no god $>$. This argument connects the logical leg of the previous argument to a classic, two-stage argument from contingency.

Start with the logical leg:

1. Suppose there is no god.

2. Then it is true that there is no god.

3. Necessarily, if it is true that there is no god, then something is true.

4. Necessarily, if something is true, then something exists.

5. Therefore, <there is no god $>$ entails < something exists>.

Next, we run a two-stage argument from contingency, such as the following:

Stage 1:

6. Something exists.

7. Necessarily, if something exists, the fact that something exists has an explanation in terms of a necessarily existing portion of reality.

8. Therefore, there is a necessarily existing portion of reality, $\mathrm{N}$.

Stage 2:

9. Necessarily, $\mathrm{N}$ lacks arbitrary, unexplained limits, where a limit is a non-maximal quantitative feature (e.g., being able to create 10 turtles).

10. Necessarily, if $\mathrm{N}$ lacks cognitive powers, then $\mathrm{N}$ has some arbitrary, unexplained limit (e.g., in greatness or in causal power). 
11. Therefore, necessarily, $\mathrm{N}$ has cognitive powers.

12. Therefore, there is a necessary mind (i.e. a god).

Combining these arguments gives us the target conclusion: $<$ there is no god $>$ entails $<$ there is a god $>$.

As with the conceptualist argument, this argument will also be controversial. Still, it is significant to see how someone could be in position to find the premises evident a priori. Recent work on modal cosmological arguments bring to light certainly purely a priori supports for the key premises (see Pruss and Rasmussen 2018). To illustrate just one line, consider this modest principle of explanation:

(P) Normally, whatever can-consistent with reasonhave an explanation has some explanation.

To lean on the side of caution, I've included the "normally" operator to allow for the possibility of exceptions (in principle). The thought is that unless one has a special reason to make an exception, one has some undefeated reason to think that any given item has a further explanation if it can (consistent with reason). Note that I am thinking of explanations as being non-circular (at least partly external to) that which is to be explained.

While this isn't the place for full defense of (P), I wish to highlight here that one may consider $(\mathrm{P})$ to be a principle of reason. For example, Koons and Pruss (2021) argue that a general principle of explanation is a precondition for empirical knowledge. Moreover, one might argue that without something like $(\mathrm{P})$, we would not be in position to suppose that some explanation of our current conscious experiences is more likely than no explanation.

Consider, next, how one might apply $(\mathrm{P})$ to the above argument. Start with stage 1 . One might think possible differences between contingent things, whether contingent turtles or contingent universes, are not relevant to at least the possibility (consistent with reason) of having some further explanation. If so, then one may apply (P) to the total of 
contingent (non-necessary) things, assuming there are contingent things. (If there are no contingent things, then everything is necessary, and we can proceed straight away to stage 2 of the argument.) Then to avoid a circular explanation, one might infer that a complete explanation of contingent things will be in terms of one or more necessary things. Call the total of necessary things (the total portion of reality that is necessary), 'N'. (For a fuller treatment of this stage of the argument and potential objections, see Pruss and Rasmussen 2018.)

Next, in support of stage 2, one might apply (P) to particular limits in N. For example, if $\mathrm{N}$ were the shape of a turtle, one might think this shape would have some further explanation, such as in terms of more fundamental features of N. Furthermore, as with contingent things, one might think that differences between limits are not relevant to the possibility of having a further explanation. At the very least, one may have some reason to expect a further explanation in any given case. If so, then unless one has special reasons to make special exceptions, one will be in position to use $(\mathrm{P})$ to shave off arbitrary, unexplained limits in $\mathrm{N}$.

The final step involves identifying a link between lacking fundamental limits and having cognitive powers. In Rasmussen 2018, I seek to support a few candidate links. To illustrate just one idea, one might argue via $(\mathrm{P})$ itself that there should be an explanation of N's lacking fundamental limits. So what might explain N's lacking fundamental limits? One might think that the only conceivable explanation that itself terminates further applications of $(\mathrm{P})$ will be in terms of a maximally great (or purely perfect) nature. ${ }^{6}$ The key

6 For an account of an absolutely perfect nature in terms of idealized excellences, see Oppy 2014. 
thought here is that a perfect, maximally great nature is the only nature that one can see, by reason, to be unable to have a further explanation; no lesser nature is evidently relevantly different from other natures that could have a further explanation. If so, then insofar as a maximally great nature would include the great powers of a necessary mind, 7 it follows that there is a necessary mind. (For a fuller and more recent treatment of this type of argument, see Rasmussen 2021.)

Whatever one thinks of this argument, it is significant to see how a classic, two-stage contingency argument might plug into a larger argument for the logical impossibility of atheism. The contingency argument is normally thought to be partly a posteriori, and the conclusion is thought to be consistent with the logical possibility of atheism. However, we have seen how one might motivate each entailment $a$ priori. The result is that someone who accepts these links in a contingency argument may have resources to deduce a stronger conclusion.

\section{Conclusion}

Many philosophers take for granted the premise that atheism is logically consistent. I suspect a significant reason for holding this view is that we tend to associate purely a priori arguments against atheism with ontological arguments. Those who are not persuaded by ontological arguments, then, are easily inclined to grant the logical consistency of atheism.

\footnotetext{
7 Arguably, a maximally great nature entails classic perfections, such as omnipotence, omniscience, and moral perfection. Any of these would in turn entail having cognitive powers.
}

Manuscrito - Rev. Int. Fil. Campinas, v. 44, n. 4, pp. 31-48, Oct.-Dec. 2021. 
Yet, what has been largely out of sight is the prospect of deducing a contradiction via a different path. In this article, we considered two potential paths: (i) from conceptualism and (ii) from contingency. Both paths include steps in classical arguments other than the ontological argument.

While not everyone will take these paths, it is significant to see that there are these paths. Many theist philosophers, at least, may be in perfect position to take one of these other paths, even if they not accept an ontological argument. These philosophers may find on these paths a new reason to think that God's existence is logically necessary.

Moreover, the significance of these paths is not merely epistemological or dialectical. The target thesis also has significant metaphysical implications. If atheism entails a contradiction, then God's existence is as sturdy as it could be thought to be. God's existence is not merely factually necessary or even metaphysically necessary (if metaphysical necessity is broader than logical necessity). God's existence is also as sturdy as the truths of logic.

Moreover, this result opens the door to a metaphysical account of logical truths as elements of God's mind. Suppose God's existence is logically necessary. Then God's mind may be a suitable home for other things that are logically necessary, including things that have the structure of a thought (e.g., abstract propositions). While this account is not required, this option is a bonus opportunity for anyone inclined to take one of the paths set out in this article.

I would like to close by sharing my own view on whether atheism entails a contradiction. I used to think that there was no purely a priori way to deduce a contradiction. I thought atheism does not entail a contradiction, and that God's existence is not logically necessary. However, after discovering the deduction via the two-stage contingency argument, I changed my mind. I now think God's existence is logically necessary on the basis of thinking through an 
extended defense of that argument. This experience tells me that the considerations of this paper have the power to change someone's thinking about God, since they changed my own.

\section{References}

Collins, Robin. "The Teleological Argument." In The Blackwell Companion to Natural Theology, edited by W. L. Craig and J.P. Moreland. Oxford: Blackwell, 2009.

Goldschmidt, Tyron. Ontological Arguments. Cambridge: Cambridge University Press, 2020

Huemer, Michael. "There is No Pure Empirical Reasoning," Philosophy and Phenomenological Research 95, no. 3 (2017): 592-613.

Oppy, Graham. Describing Gods: an Investigation of Divine Attributes. Cambridge: Cambridge University Press, 2014.

Pruss, Alexander \& Rasmussen, Joshua. Necessary Existence. Oxford: Oxford University Press, 2019.

Pruss, Alexander \& Koons, Robert. "Skepticism and the Principle of Sufficient Reason," Philosophical Studies 178, no. 4 (2021): 1079-1099.

Rasmussen, Joshua. How Reason Can Lead to God. Illinois: Intervarsity Press, 2019. . "From Necessary Truth to Necessary Existence," Polish Journal of Philosophy 7, no. 1 (2013): 19-30. . "The Argument from Contingency." In Contemporary Arguments in Natural Theology, edited by Colin Ruloff and Peter Horban. New York: Bloomsbury, 2021. 
Rumfitt, Ian. "Logical Necessity." In Modality: Metaphysics, Logic, and Epistemology, edited by Bob Hale and Aviv Hoffman, Oxford: Oxford University Press, 2010.

Smith, Quentin. "The Conceptualist Argument for God's Existence," Faith and Philosopby 11, no. 1 (1994): 3849.

Swinburne, Richard. The Existence of God. Oxford: Clarendon Press, 1979. . "What Kind of Necessary Being Could God Be?" In Ontological Proofs Today, edited by Miroslaw Szatkowski. Ontos Verlag, 2012.

Welty, Greg \& Anderson, James. "The Lord of Noncontradiction: An Argument for God from Logic," Philosophia Christi 13, no. 2 (2011): 321-38.

$(c c) E Y$ 